\title{
Monitoring the Early-Age Shrinkage Cracking of Concrete with Superabsorbent Polymers by Means of Optical Fiber (SOFO) Sensors
}

\author{
José R. Tenório Filho ${ }^{1,2}$, Didier Snoeck ${ }^{1}$ and Nele De Belie ${ }^{1}$ \\ ${ }^{1}$ Magnel Laboratory for Concrete Research, Department of Structural Engineering, Faculty of \\ Engineering and Architecture, Ghent University, Technologiepark Zwijnaarde 60, B-9052 Ghent, \\ Belgium; email: roberto.tenoriofilho@ugent.be,didier.snoeck@ugent.be,nele.debelie@ugent.be \\ ${ }^{2}$ SIM vzw, Technologiepark 48, Zwijnaarde B-9052 Ghent, Belgium
}

\begin{abstract}
Concrete structures are subjected to shrinkage since the moment when the water makes contact with the cement. From that moment on, depending on the concrete composition and its curing conditions, chemical, autogenous and drying shrinkage might increase the risk of early-age cracking. Once a crack is formed, it may become the preferential path for the ingress of many aggressive agents inside the structure increasing the probability of damage due to corrosion, carbonation and other mechanisms. The use of superabsorbent polymers (SAPS) has been extensively studied to reduce the shrinkage cracking risk in mortar specimens by acting as internal curing agent to mitigate autogenous shrinkage. In this paper, a commercially available SAP was investigated as shrinkage reducing agent by means of internal curing in concrete specimens. The shrinkage of the concrete was monitored for 28 days with both a demountable mechanical strain gange (DEMEC) and optical fiber sensors (SOFO). The SAP-containing concrete showed a complete mitigation of autogenous shrinkage during 28 days of measurement, for both methods. The SOFO sensors showed the occurrence of cracks after 7 days for the reference mixture, while for the SAP containing mixture, no crack was identified during the 28 days of measurements.
\end{abstract}

Keywords: Early-Age Cracking, Superabsorbent Polymers, Internal Curing, SOFO Sensors.

\section{Introduction}

Shrinkage in concrete structures has been the focus of many studies, and lately, a lot of attention has been given to autogenous shrinkage. The autogenous shrinkage occurs in all kinds of concrete structures at different levels. In ordinary concrete structures (with water-to-cement ratio above 0.42 ) it is not such a prominent phenomenon but it may increase the risk of cracking, especially when supplementary cementitious materials are used (Jian et al., 2014; Wu et al., 2017). On the other hand, it may be the main cause of early-age cracking in systems with waterto-cement/binder ratio lower than 0.42 (ultra-high performance concrete, for example) (Jensen and Hansen, 2001a; Jensen and Hansen, 2001b).

Recently, a lot of research has been developed aiming to use the SAPs to reduce/mitigate shrinkage in cementitious materials, most of it at mortar or paste level (Jensen, 2008; Snoeck, 2015; Snoeck and De Belie, 2015; Snoeck et al., 2017; Tenório Filho et al., 2018; De Meyst et al., 2019; Snoeck et al., 2018; Geiker et al., 2004) and some in high performance concrete compositions (HPC) (Jian et al., 2014; Wu et al., 2017; Craeye et al. 2011; Pierard et al., 2006), all showing that a dosage of SAPs in the range of $0.2-0.6 \%$ with respect to the cement mass should be enough to considerably reduce or complete mitigate the deformation due to autogenous shrinkage. 
Superabsorbent polymers (or hydrogels) are a natural or synthetic water-insoluble 3D network of polymeric chains cross-linked by chemical or physical bonding. They possess the ability to take up a significant amount of fluids from the environment (in amounts up to 500 times their own weight) (Mechtcherine and Reinhardt, 2012). Once in contact with the mixing water of the cementitious material, the SAPs absorb and retain a certain amount of the water (depending on their absorption capacity), later on acting as water reservoirs for the system, keeping its levels of internal relative humidity high for a considerable time frame (depending on the SAP used, even up to 28 days (Snoeck et al., 2017)).

Up to now, most of the studies investigating the deformation due to autogenous shrinkage of concrete have relied on test methods based on linear measurements performed with the use of length transducers placed on the top surface of prismatic specimens, with the measurements starting at different times (for example at $6 \mathrm{~h}, 9 \mathrm{~h}$ and $24 \mathrm{~h}$ ) (Craeye et al., 2011; Pierard et al., 2006; Sven and Reinhardt, 2006; ASTM, 2017; Barcelo et al., 2005).

For the case of concrete structures, the crack formation or presence of internal voids and discontinuities might lead to different responses in different locations. For that reason, the use of long-gauge deformation sensors allows a more global and precise understanding of the material/structure under investigation.

In this paper, long-gauge deformation sensors based on low-coherence interferometry in optical fiber sensors are used to investigate the influence of superabsorbent polymers on the autogenous shrinkage of concrete mixtures. The material response due to shrinkage deformation is also evaluated by a more traditional approach, using a demountable mechanical strain gauge (DEMEC).
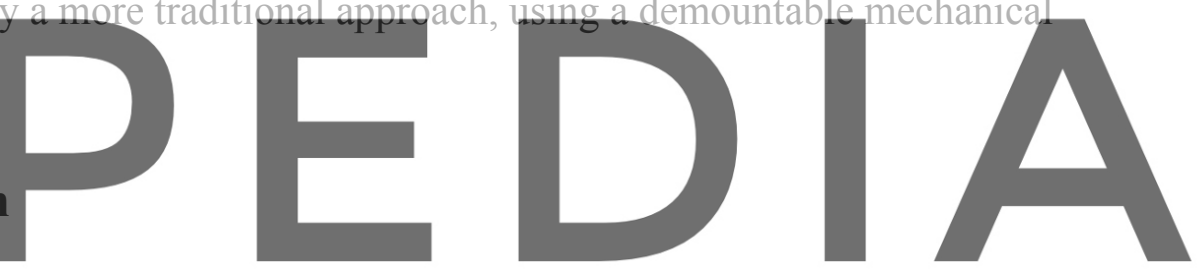

2.1 Materials and Characterization of the SAP

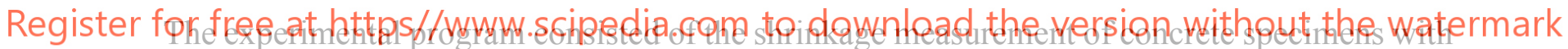
and without SAPs by means of manual measurements with a demountable mechanical strain gauge (DEMIEC) and automatic measurements with optical fiber sensors (SOFO).

All tests were performed on concrete mixtures produced with cement type CEM III-B 42.5N - LH/SR (CBR, Belgium); a polycarboxylate superplasticizer (Tixo, 25\% conc., BASF, Belgium, at a constant dosage of $1.8 \%$ in relation to the cement mass); sea sand $0 / 4$ (absorption of $0.4 \%$ in mass); sea sand $0 / 3$ (absorption of $0.3 \%$ in mass); limestone $2 / 20$ (absorption of $0.5 \%$ in mass) and a commercial superabsorbent polymer identified as SAP1. More details about the compositions of the concrete mixtures are given in Table 1.

SAP1, made by SNF Floerger (France) is a cross-linked acrylate copolymer produced by bulk polymerization and has a mean particle size $\left(\mathrm{d}_{50}\right)$ of $360 \mu \mathrm{m}$. It has been previously studied as internal curing agent and self-sealing/healing promoter for mortar mixtures (Snoeck, 2015; Tenório Filho et al., 2018). 
Table 1. Composition of the studied concrete mixtures, values in $\mathrm{kg} / \mathrm{m}^{3}$.

\begin{tabular}{cccccccc}
\hline Mixture & Cement & Sand 0/3 - & Limestone & & & Additional & $\mathrm{w} / \mathrm{c}_{\text {(total }}$ \\
& & Sand 0/4 & $2 / 20$ & Superplasticizer & SAP & water & {$[-]$} \\
\hline REF0.46 & 356 & $421-343$ & 1086 & 6.35 & 0 & 0 & 0.46 \\
REF0.57 & 340 & $406-331$ & 1046 & 6.12 & 0 & 0 & 0.57 \\
C_SAP1 & 340 & $406-331$ & 1046 & 6.12 & 1.70 & 37.42 & 0.57 \\
\hline
\end{tabular}

Dry materials were first mixed for 1 min (including SAPs, when present), then the mixing water and superplasticizer were added and mixed for an additional $2 \mathrm{~min}$. When SAPS were present, the additional entrained water was added during the third minute and the mixing proceeded for an additional $2 \mathrm{~min}$. The total mixing time was $3 \mathrm{~min}$ for the reference mixture and 5 min for the SAP-containing mixtures. Prior to the concrete mixing and testing, the superabsorbent polymers were tested to assess their absorption capacity. The filtration method was performed in compliance with Snoeck et al. (2018). The SAPs were tested in demineralized water and in a cement filtrate solution prepared with the same cement used to produce the concrete mixtures. The cement filtrate was produced with cement and demineralized water at a proportion of 1:5 in mass.
The absorption capacity was also studied in cement pastes
of slump tests. The measurements were performed exactly 10
SAPs with the mixing water.
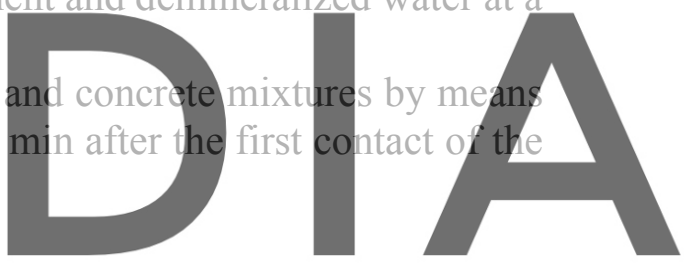

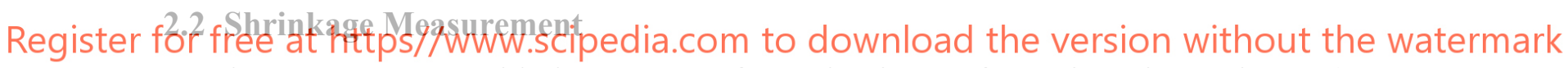
For the measurements with the DEMEC, for each mixture, four prismatic specimens (100 mm $\times 100 \mathrm{~mm} \times 400 \mathrm{~mm}$ ) were cast and cured for $23 \mathrm{~h}$ in a room with controlled atmosphere of 20 $\pm 2{ }^{\circ} \mathrm{C}$ and $\mathrm{RH}>95 \%$. Right after casting, the free surface of the specimens was covered with a layer of plastic foil, attached to the mold with a thin layer of vaseline to improve the adhesion and prevent drying.

After the curing period, the demolded specimens were wrapped with aluminum tape to avoid moisture exchange with the environment, in this way, reducing the effects of drying shrinkage. Two measuring points were glued to the surfaces of the specimens (except for the troweled surface due to the fact of shape irregularities that could hinder the measurements), placed 200 $\mathrm{mm}$ apart on the central line of the specimens' surface. In total, each specimen had three measuring surfaces. The measurements were performed once per day for 28 days and started $24 \mathrm{~h}$ after the first contact of cement with the mixing water. The test was conducted in a room with a controlled atmosphere of $20 \pm 2{ }^{\circ} \mathrm{C}$ and $60 \pm 5 \% \mathrm{RH}$.

For the measurements with the SOFO sensors, given the availability and the costs, only REF0.46 and the SAP-containing mixture were tested. The sensors used were produced by SMARTEC (Switzerland). The sensors consist of an active part, that measures the deformation, and a passive part, which transmits the data to a reading unit (Figure 1). The sensors used in 
this investigation had an active length of $250 \mathrm{~mm}$ and a passive length of $10 \mathrm{~m}$.

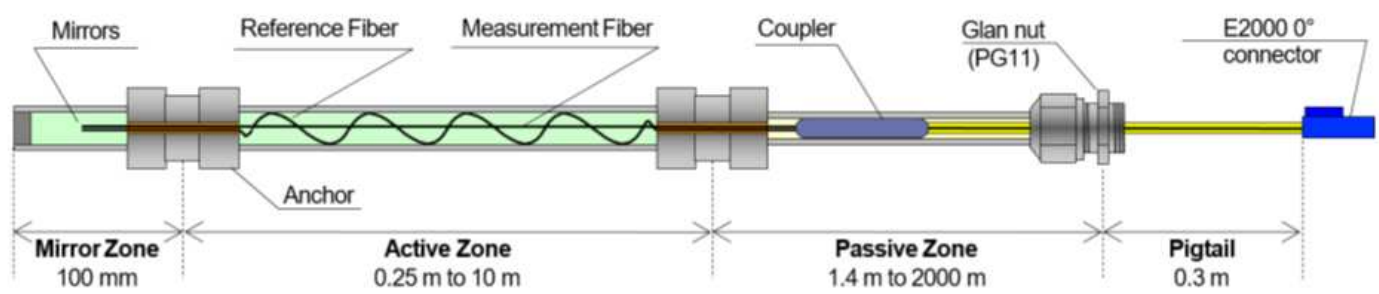

Figure 1. Illustration of the sensor. Courtesy of SMARTEC.

The specimens used for the measurements with the sensors had the same dimensions as the ones used with the DEMEC device (100 mm x $100 \mathrm{~mm}$ x $400 \mathrm{~mm})$. The sensors were embedded in the concrete, attached to a steel rebar with a diameter of $\varnothing 6 \mathrm{~mm}$ and length of $440 \mathrm{~mm}$, placed at the middle height of the mold in order to ensure a correct position of the sensors. After casting and during the test, the specimens were covered with plastic foil to prevent drying. The specimens were cured for $23 \mathrm{~h}$ in a room with controlled atmosphere of $20 \pm 2{ }^{\circ} \mathrm{C}$ and $\mathrm{RH}>$ $95 \%$.

The measurements were performed automatically, every 10 min for 28 days, starting 30 min after concrete mixing. The tests were performed in a room with a controlled atmosphere of 20 $\pm 2{ }^{\circ} \mathrm{C}$ and $60 \pm 5 \% \mathrm{RH}$. The values of strain were zeroed at the fluid-solid transition point. The transition point was determined considering t became zero (Tenório Filho autogenous shrinkage

\section{Results and Discussion}
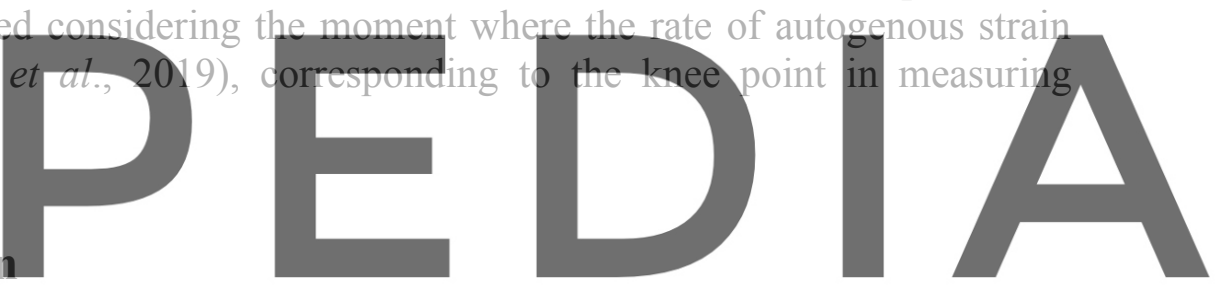

Figure 2 shows the water uptake (g of water/g of SAP) of the SAPs in demineralized water,

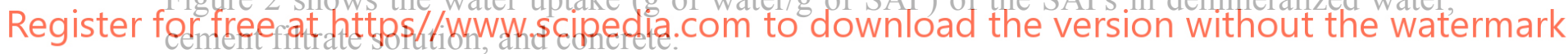

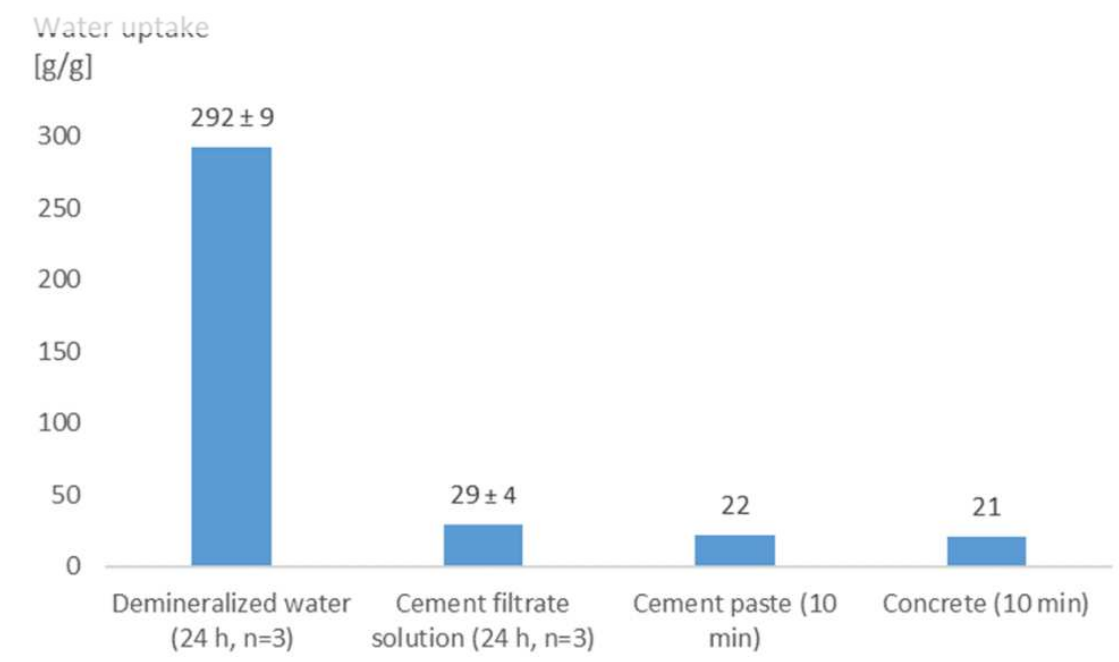

Figure 2. Water uptake $[\mathrm{g} / \mathrm{g} \mathrm{SAP}]$ of the SAP in demineralized water, cement filtrate solution, cement paste and concrete. 
The absorption capacity is noticed to decrease from demineralized water to cementitious fluids, which was already expected due to presence of monovalent and divalent ions (i.e. $\mathrm{Na}^{+}$, $\mathrm{K}^{+}, \mathrm{Ca}^{2+}$ ) in the cement filtrate, cement paste and concrete (Kang et al., 2017; Kang et al., 2018). The results with the cement paste show that such method can be used as a suitable estimation for the absorption capacity of the SAPs in concrete.

Figure 3 shows the shrinkage strain measured with the DEMEC for the mixtures REF0.46, REF0.57 and C_SAP1. The reference mixtures shows both only shrinkage during the whole time of tests and the strain values are comparable to those found in literature for concrete mixtures with similar composition and the same type of cement (Lura et al., 2001). On the other hand, the SAP-containing mixture show a complete mitigation of the shrinkage strain during the 28 days.

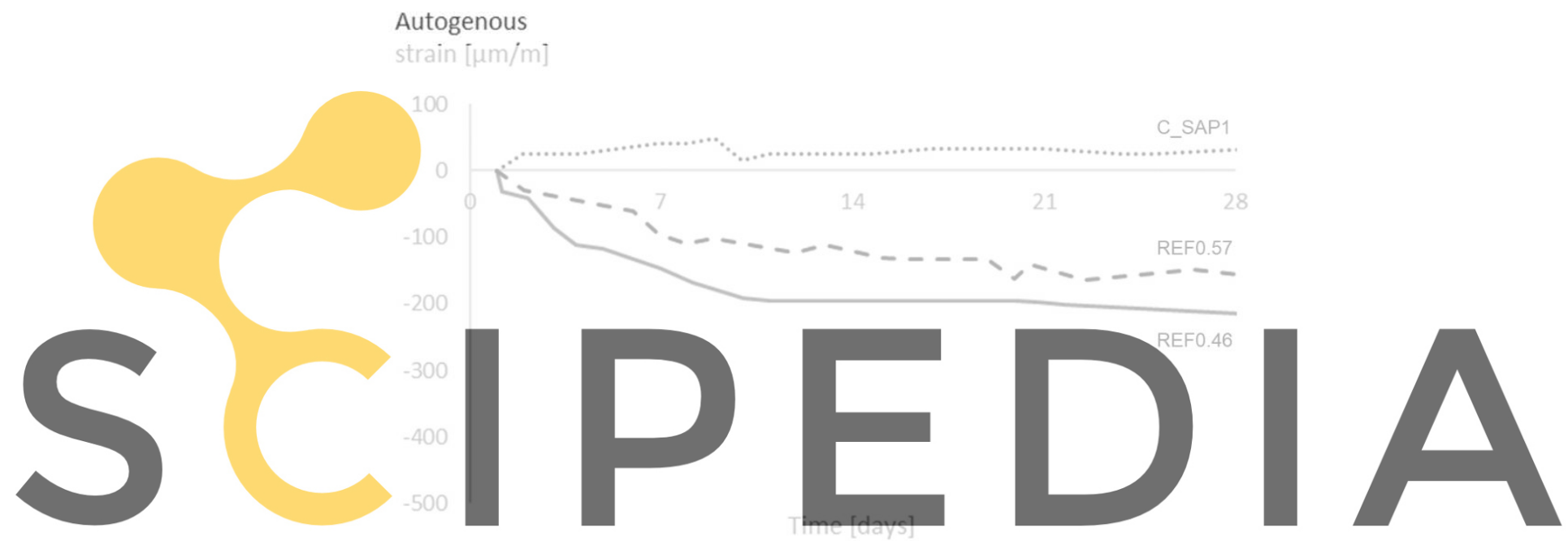

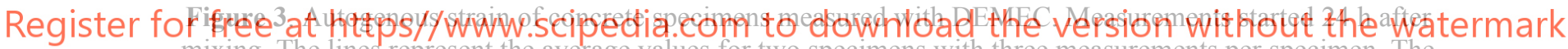
mixing. The lines represent the average values for two specimens with three measurements per specimen. The maximum standard deviation found was $\pm 50 \mu \mathrm{m}$.

When comparing the mixtures REF0.57 and C_SAP1, even though they were produced with the same water-to-cement ratio (0.57), the mixture REF0.57 is not able to mitigate the shrinkage strain (but only to reduce it in comparison with the mixture REF0.46).

In such mixture, the total water content is available for being used in the hydration from the beginning, which might increase the effects of the chemical shrinkage. With the use of SAPs, part of this water is stored inside the polymer particles being released at the appropriate time to mitigate the autogenous shrinkage. In this way, the used SAPs can be considered very efficient to be used as internal curing agent, completely mitigating the autogenous shrinkage and preventing the formation of early-age cracks (which was also verified with the use of the SOFO sensors).

Figure 4 shows the autogenous strain measured with the SOFO sensors for the mixtures REF0.46 and C_SAP1. As also observed in Figure 3, the SAP-containing mixture shows a complete mitigation of shrinkage while the reference mixture (REF0.46) only shows shrinkage. Another interesting feature noticed is the existence of some "jumps" in the graph that are only 
observed for the reference mixture. These "jumps" are assumed to be indications of crackformation.

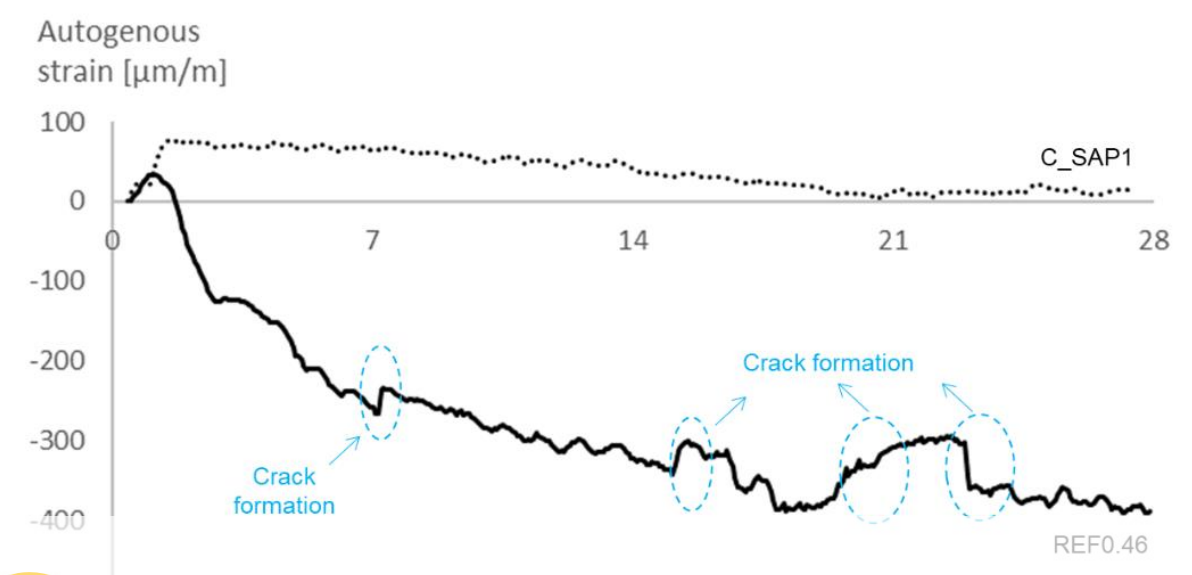

Figure 4. Autogenous strain of concrete specimens measured with SOFO sensors. Measurements zeroed at the fluid-solid transition point for each mixture. Crack formation is also indicated.

To verify whether the samples possessed internal micro-cracking, after the 28 days of measurements, the specimens were cut and investigated by neans of an optical microscopy. This analysis confirmed the existence of small cracks (up to $50 \mu \mathrm{m}$ ) in the reference mixture along the length of the sensor (Figure 5). The same cracks were not observed in the mix ture
C_SAP1. Also, no debonding was notieed between the sensors and the cement matrix. Register for free at https//www.scipedia.com to download the version without the watermark
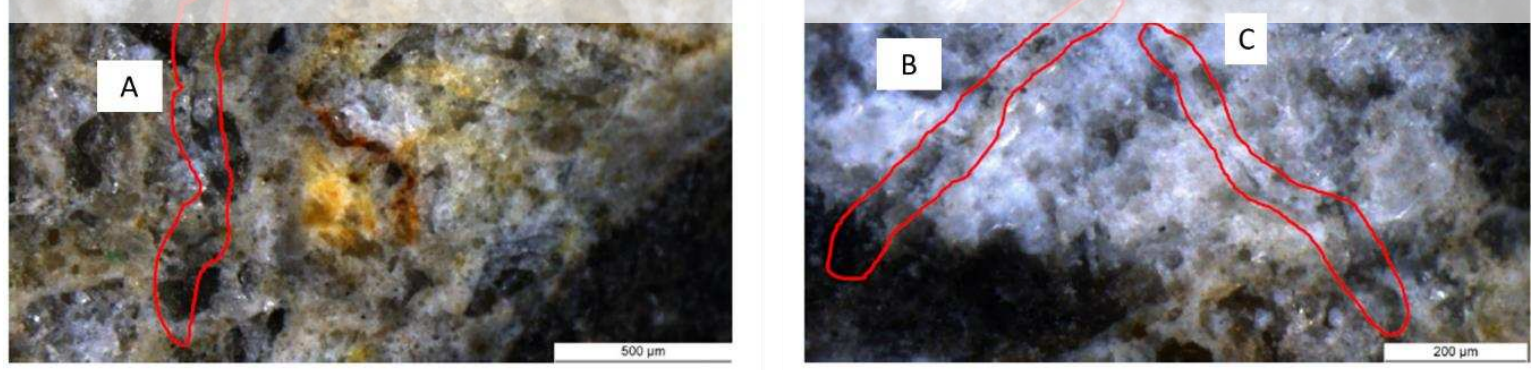

Figure 5. Micro-cracks identified in the cement matrix in the surroundings of the sensor.

\section{Conclusions}

- The SAP-containing mixture was able to show a significant reduction in the shrinkage strain in comparison to the reference mixtures with and without additional water, fully mitigating the autogenous shrinkage;

- Both the DEMEC and the SOFO sensors efficiently captured the effect of the SAPs in 
comparison to the reference mixture, but the absolute values of strain are different. This was the case especially for the reference mixture, as a consequence of the different coverages used to avoid drying;

- The optical fiber sensors were able to provide an indication for the moment of crack formation without the need of additional tests or indirect measurements;

- While they might represent a costly investment, in comparison with other techniques, the use of the embedded sensors brings more advantages, higher level of precision and reduced person-hours in the monitoring of shrinkage deformation in the concrete, which can be even more valuable when considering the monitoring of larger scale specimens and structures.

\section{Acknowledgements}

The authors thank Tom Stulemeijer, Dieter Hillewaere and Tommy De Ghein for the help with the experimental work. As a Postdoctoral Research Fellow of the Research Foundation-Flanders (FWO-Vlaanderen), D. Snoeck would like to thank the foundation for the financial support (12J3620N).

\section{Funding}

The work has been financed by SIM program SHE (Engineered Self-Healing Materials) within the ICON project iSAP (Innovative SuperAbsorbent Polymers for crack mitigation and increased service life of concrete structures).
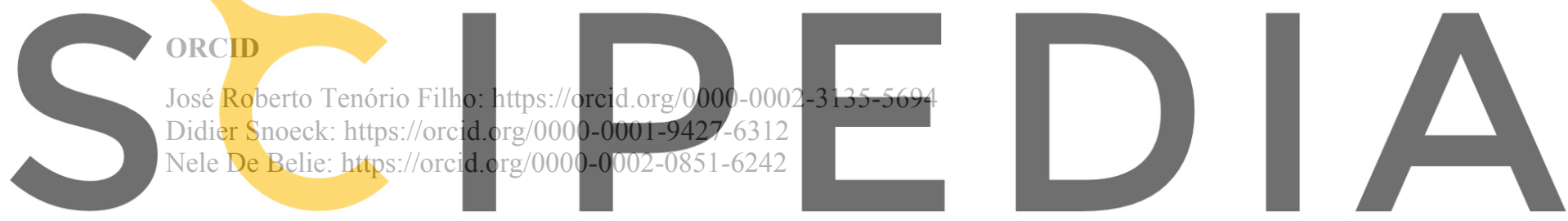

Register for free at https//www.scipedia.com to download the version without the watermark

Barcelo, L., M. Moranville and B. Clavaud (2005). Autogenous shrinkage of concrete: a balance between autogenous swelling and self-desiccation. Cement and Concrete Research, 35(1): p. 177-183.

De Mieyst, L., et al. (2019). Parameter Study of Superabsorbent Polymers (SAPs) for Üse in Durable Concrete Structures. Materials, 12(9).

Geiker, M.R., D.P. Bentz and O.M. Jensen (2004). Mitigating autogenous shrinkage by internal curing. HighPerformance Structural Lightweight Concrete, 218: p. 143-154.

International, A., ASTM C157 / C157M-17 (2017). Standard Test Method for Length Change of Hardened Hydraulic-Cement Mortar and Concrete. West Conshohocken.

Jensen, O.M. and P.F. Hansen (2001a). Autogenous deformation and RH-change in perspective. Cement and Concrete Research, 31(12): p. 1859-1865.

Jensen, O.M. and P.F. Hansen (2001b). Water-entrained cement-based materials I. Principles and theoretical background. Cement and Concrete Research, 31(4): p. 647-654.

Jensen, O.M. (2008). Use of Superabsorbent Polymers in Construction Materials. Microstructure Related Durability of Cementitious Composites, Vols 1 and 2, 61: p. 757-764.

Jiang, C.H., et al. (2014). Autogenous shrinkage of high performance concrete containing mineral admixtures under different curing temperatures. Construction and Building Materials, 61: p. 260-269.

Kang, S.H., S.G. Hong and J. Moon (2017). Absorption kinetics of superabsorbent polymers (SAP) in various cement-based solutions. Cement and Concrete Research, 97: p. 73-83.

Kang, S.H., S.G. Hong and J. Moon (2018). Importance of monovalent ions on water retention capacity of superabsorbent polymer in cement-based solutions. Cement \& Concrete Composites, 88: p. 64-72. 
Lura, P., K. van Breugel and I. Maruyama (2001). Effect of curing temperature and type of cement on early-age shrinkage of high-performance concrete. Cement and Concrete Research, 31(12): p. 1867-1872.

Mechtcherine, V. and H.W. Reinhardt (2012). Application of Super Absorbent Polymers (SAP) in Concrete Construction, in State-of-the-Art Report Prepared by Technical Committee 225-SAP. RILEM. p. 165.

Snoeck, D. (2015). Self-Healing and Microstructure of Cementitious Materials with Microfibres and Superabsorbent Polymers, in Faculty of Architecture and Engineering. 2015, Ghent University: Ghent, Belgium.

Snoeck, D. and N.D. Belie (2015). Effect of superabsorbent polymers, superplasticizer and additional water on the setting of cementitious materials. International Journal of 3R's, 5(3): p. 721-729.

Snoeck, D., C. Schrofl and V. Mechtcherine (2018). Recommendation of RILEM TC 260-RSC: testing sorption by superabsorbent polymers (SAP) prior to implementation in cement-based materials. Materials and Structures, 51(5).

Snoeck, D., L. Pel and N. De Belie (2018). Superabsorbent polymers to mitigate plastic drying shrinkage in a cement paste as studied by NMR. Cement \& Concrete Composites, 93: p. 54-62.

Snoeck, D., L. Pel and N. De Belie (2017). The water kinetics of superabsorbent polymers during cement hydration and internal curing visualized and studied by NMR. Scientific Reports, 7.

Snoeck, D., O.M. Jensen and N. De Belie (2015). The influence of superabsorbent polymers on the autogenous shrinkage properties of cement pastes with supplementary cementitious materials. Cement and Concrete Research, 74: p. 59-67.

Snoeck, D. (2015). Self-Healing and Microstructure of Cementitious Materials with Microfibres and Superabsorbent Polymers, in Faculty of Architecture and Engineering. 2015, Ghent University: Ghent, Belgium.

Sven Mönnig and H.-W. Reinhardt (2006). Results of a comparative study of the shrinkage behaviour of concrete and mortar mixtures with different internal water sources. in International RILEM Conference on Volume Changes of Hardening Concrete: Testing and Mitigation. 2006. Lyngby, Denmark: RILEM Publications

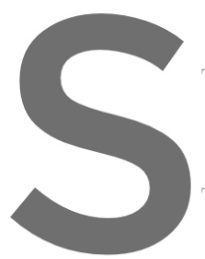
SARL

Tenório Filho, J.R., D. Snoeck and behavior due to autogen do Iguacu, Brazil: Brazili

Tenório Filho, J.R.; Perei Approaches for the Ti Polymers. Materials, 12, 2962.
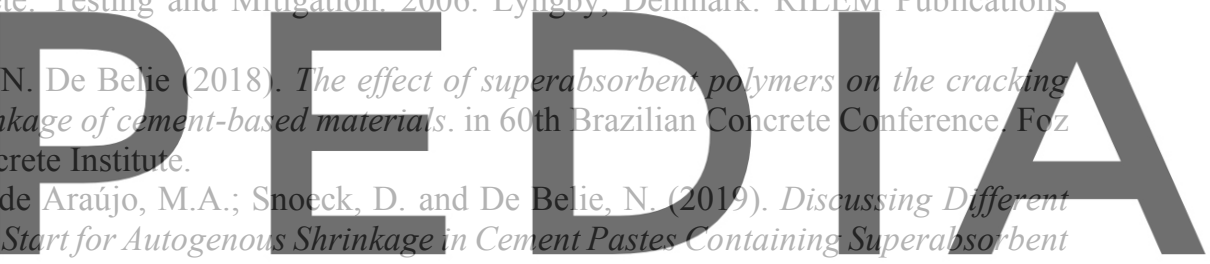